\title{
Cytochrome Oxidase and Functional Coding in Primate Striate Cortex: A Hypothesis
}

\author{
J. AlLMaN* AND S. ZuCKeR ${ }^{\dagger}$ \\ *Division of Biology, California Institute of Technology, Pasadena, California 91125; \\ $\dagger$ Department of Electrical Engineering and the Canadian Institute for Advanced Research, McGill University, \\ Montreal, Quebec, Canada H3A $2 A 7$
}

In 1978, Margaret Wong-Riley stained sections of squirrel monkey striate cortex for the activity of the mitochondrial enzyme, cytochrome oxidase, and noticed a periodic distribution of "puffs" of increased enzyme activity in layers 2 and 3 (letter to D. Hubel cited in Livingstone and Hubel [1984]). Her discovery anticipated a whole series of anatomical and physiological findings from many laboratories that correlated with the distribution of this enzyme in the striate cortex of primates, yet there has never been a satisfactory explanation as to why the distribution of this enzyme, crucial for aerobic energy metabolism, would be related to the functional organization of visual cortex (Martin 1988). The puffs have also been called blobs, spots, dots, and patches, with the term blob used most frequently.

When the striate cortex is viewed from above, the blobs form a periodic array intercalated within a lattice of lower cytochrome oxidase concentration. We propose that the distinction between the blobs and the lattice is related to two different modes for representing stimulus variables. We submit that scalar variables related to the intensity of the stimulus are represented in the blobs. Intensity information is encoded explicitly over a very broad dynamic range, in which activity is proportional to the intensity variable (e.g., contrast). This encoding strategy requires that neurons have the energetic capacity to sustain a broad range of activity levels, which in turn is related to the high concentration of cytochrome oxidase. The situation is analogous to red muscle, which also is rich in cytochrome oxidase and which is able to maintain a sustained level of contraction over time (Needham 1971).

We propose that in the surrounding lattice of lower cytochrome oxidase concentration, geometric variables are carried by neurons with orientation preferences and lead to different representational requirements. Each stimulus orientation is possible at every retinotopic location, and each is represented explicitly within an orientation hypercolumn. Activity varies with how well each individual orientation matches image structure at that location. However, there is rarely more than one orientation at any retinotopic location, so, on average, most oriented cells in each hypercolumn are quiet. The preference of these neurons for higher spatial frequencies (and possibly binocular disparities) further reduces the statistical probability that they will be active at any particular instant in time. The average level of neural activity over time is thus much less in the lattice than in the blobs, which is consistent with the lower levels of cytochrome oxidase in the lattice. There is an analogy with white muscle, which contains less cytochrome oxidase and typically has short bouts of rapid contraction interspersed with longer resting periods.

We review the main empirical findings that have led us to this hypothesis. Tootell et al. (1988b) showed that the blobs were preferentially responsive to low spatial frequency gratings, whereas the lattice preferred higher spatial frequencies in experiments in which the functional activity of macaque monkey striate cortex was mapped with 2-deoxyglucose autoradiography. Silverman et al. (1989) found a strong negative correlation between cytochrome oxidase concentration and spatial frequency preference in electrophysiological recording experiments. Probably related to the spatial frequency organization of the blobs and the intervening lattice is the observation of Livingstone and Hubel (1984) that blob neurons tend to be much less sensitive to the orientation of elongated stimuli than are neurons in the lattice.

Livingstone and Hubel (1984) also noted that many neurons in the blobs were preferentially activated by stimulus color, and they found "double-opponent" color cells in the blobs. Tootell et al. (1988a) found that the blobs were more activated by colored stimuli than by gray stimuli of equal luminance. However, there are comparative data which suggest that the blobs have important functions that transcend color vision. Galagos, lorises, and owl monkeys, which are nocturnal primates ${ }^{1}$ and therefore live in dim lighting conditions in which color vision is virtually impossible, nevertheless have well-developed cytochrome oxidase

\footnotetext{
${ }^{1}$ Galagos appear to be strictly nocturnal. They become active in the evening twilight at the time that human observers can no longer see color and cease to be active in the morning twilight when humans can just begin to discern color (Martin 1990). Owl monkeys are less strictly nocturnal. The activity cycle in owl monkeys varies in different parts of South America. In Peru, they are nocturnal; in Paraguay, they are active for several hours after sunrise and for several hours before sunset (Wright 1989). In the laboratory, owl monkeys are often active during the day, whereas galagos housed under the same conditions are active only at night (J. Allman, pers. obs.). Jacobs (1977) found that ow] monkeys have a weakly developed capacity for color vision. Wikler and Rakic (1989) found that cones, identified immunocytochemically, are relatively abundant in galagos and owl monkeys. Possibly the cones in these nocturnal species scrve to regulate daily activity cycles.
} 
blobs (Horton and Hubel 1981; Horton 1984; Tootell et al. 1985; McGuinness et al. 1986; Condo et al. 1987; J. Allman and E. McGuinness, in prep.). There also are two diumal primates, Hapalemur griseus and Propithecus verrauxi, that lack blobs, although the color vision capacities of these rare prosimians are unknown (McGuinness et al. 1986; J. Allman and E. McGuinness, in prep.). Blobs also are absent in a diurnal nonprimate with well-developed color vision, the tree shrew (Horton 1984; Jacobs and Neitz 1986; WongRiley and Norton 1988).

In macaque monkeys, the blobs are located in the centers of ocular dominance columns (Horton and Hubel 1981; Wong-Riley and Carroll 1984; Blasdel and Salama 1986) and are driven strongly by one eye (T"so and Gilbert 1988). The intervening lattice appears to have more complex binocular interactions. In this context, it is interesting to note that the lattice has higher concentrations of the calcium-binding protein, calbindin (Celio et al. 1986). Calbindin is abundant in neural structures in which precise timing of signals is important, such as the time-dependent pathways in electroreceptive fish (Maler et al. 1984) and the nuclei responsible for interaural time comparisons for sound localization in owls (Takahashi et al. 1987). There is a precise trade-off between spatial and temporal binocular disparity in stereopsis (Burr and Ross 1979); it is an intriguing possibility that the distribution of calbindin in the lattice is related to precise spatial-temporal binocular processing.

Maguire and Baizer (1982) investigated the responses of neurons in striate cortex of awake monkeys to different luminances against a constant background. They found that cells lacking orientation selectivity responded in a graded fashion to as much as $4 \log$ units of variation in luminance from threshold to saturation. ${ }^{2}$ At saturation, some of these nonoriented cells reached firing rates of 300 spikes per second, which is remarkably high for cortical neurons. The oriented cells usually responded to about $1 \mathrm{log}$ unit of variation from threshold to saturation. These authors did not localize their recording sites to specific structures within striate cortex, but is it likely that their nonoriented cells were either in layer $4 \mathrm{C}$ or in the blobs, whereas their oriented cells were probably in the lattice.

The two styles of coding proposed in our hypothesis are classical, although the application to the bloblattice system is novel. Intensity coding may be conceptually viewed as the more primitive form and is more commonly described in the brain stem oculomotor system, whereas coding in proportion to strength of match is more commonly described in the cortex (Marr 1970; Barlow 1972; Ballard 1986).

\footnotetext{
"These neurons might correspond in part to the "luxotonic" cells recorded from striate cortex of the squirrel monkey (Bartlett and Doty 1974) and the macaque (Kayama et al. 1979). The luxotonic cells were defined as having a maintained discharge to diffuse light and/or having a discharge that varied monotonically with change in light intensity over a range of at least $3 \mathrm{log}$ units.
}

Although the above data indirectly support our hypothesis that cells containing high concentrations of cytochrome oxidase in the blobs are coding intensity variables, and the lattice cells are coding the match between geometric variables and the image, testable predictions do arise. The first series of predictions involve the coding of contrast, and the most direct of these is that, if contrast sensitivity were measured for blob cells, they would have the relationship to lattice cells illustrated in Figure 1. The contrast sensitivity curves that have been measured in striate cortex are for cells with an orientation preference (Sclar et al. 1989) and agree with the prediction for lattice cells; no direct measurements for blob cells have been made to our knowledge.

A second prediction of our hypothesis is that the blob system should exhibit relatively little contrast adaptation or gain control. This differs from the lattice system, which could use contrast adaptation to extend its operating range from dim to bright light. However, if the blob system were to adapt, then the baseline for calibrating contrasts would be lost. Blob cells would resemble lateral geniculate neurons in this regard (Derrington and Lennie 1984).

Third, if the blob system is coding contrast, then how can luminance values be recovered? One possibility is suggested by interpreting the circular surround receptive fields mathematically and then simply adding the responses together from cells spanning a range of receptive field sizes (Zucker and Hummel 1986). This suggests mapping the spatial properties of receptive fields for cells within blobs, and that a range of sizes will be found. The findings of Silverman et al. (1989) are consistent with this suggestion.

Surfaces can not only be covered with paint to give them contrast and color, but they can also be sprinkled with spots. Our next class of predictions are thus related to textures lacking orientation, such as salt-andpepper patterns. Psychophysical evidence (Barlow 1979) indicates that density is a key property of such patterns, and it is another basic scalar intensity variable. Thus, we predict that the density of unoriented texture patterns is carried by the blob system. Furthermore, it follows that the smearing of textures outside of borders should be no more noticeable than the smear-

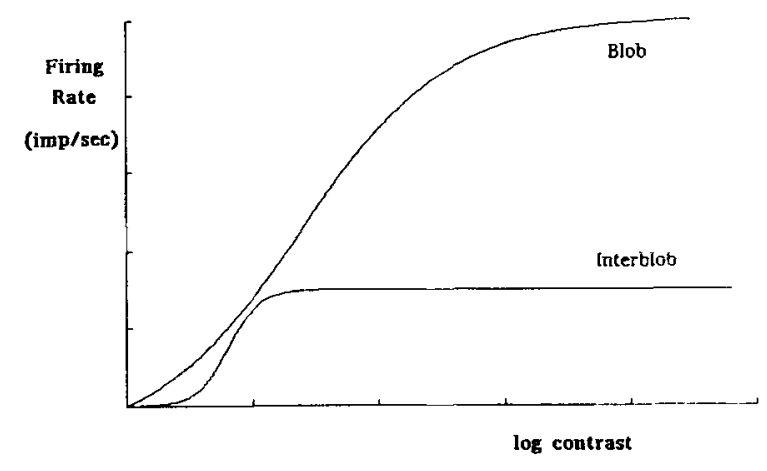

Figure 1. Predicted contrast sensitivity curves for blob and lattice neurons. 
ing of color and contrast (for examples, see Livingstone and Hubel 1987). If there is no context provided by the geometric system, and if a class of blob cells represents the density of small spots, then there will be no geometric anchors to hold the dots in place. They would thus be free to drift in position and depth; perhaps this is the basis of the autokinetic effect.

The blobs are reduced following eye removal or tetrodotoxin injection into the linked eye (Wong-Riley and Carroll 1984; Wong-Riley et al. 1989). However, the blobs are not absolutely dependent on visual input. The blobs are present in newborn primates (Horton 1984) and even in monkeys that have had their eyes removed well before birth (Kuljis and Rakic 1990). One possible explanation for this is that a sizable portion of the neurons in the blobs may be very nonselective and respond simply to a graded input encoding contrast, whereas the lattice circuitry requires a precise coincidence of inputs. Thus, the surviving population of neurons in the lateral geniculate nucleus in monkeys with their eyes removed well before birth might be sufficient to provide a tonic drive to the blobs and thus engage their metabolic machinery.

The blob-lattice distinction is not an absolute dichotomy. There is a gradient in the concentration of cytochrome oxidase between the blobs and the lattice (Silverman et al. 1989). Similarly, the blob neurons are not uniform in cytochrome oxidase content (WongRiley et al. 1989). In particular, one class of blob neuron (type $\mathrm{C}$ ) is much richer in cytochrome oxidase. Type $\mathrm{C}$ neurons constitute about one quarter of the blob population, and Wong-Riley and her collaborators have suggested that they correspond to the non-colorcoded blob neurons that comprise a similar portion of the recording sample for blob neurons (Livingstone and Hubel 1984; T'so and Gilbert 1988). We hypothesize that this cytochrome-oxidase-rich population of blob neurons encodes contrast over a broad dynamic range and serves as the basis for a cortical brightness constancy system. We suspect that cytochromeoxidase-rich neurons may constitute a larger portion of the blob population in nocturnal species. There is considerable evidence that primates evolved from nocturnal ancestors (Allman 1977), and the blobs may have developed originally as part of a cortical system for brightness constancy in highly visual animals living in a dimly illuminated environment. When primates became diurnal, they may have elaborated this system to encompass the color-specific lightnesses for determining color constancy.

In summary, the blob system is involved in color, contrast, and texture density; in short, in carrying scalar intensity variables. We are suggesting a difference in the interpretation of activity for neurons in the blobs and lattice: Firing rate encodes intensity in the blobs and "strength of match" in the lattice. Intuitively, we find this new view compelling: Otherwise, why would the visual system have evolved the blobs if it were simply "colorizing" the outlines provided by the lattice system?

\section{ACKNOWLEDGMENTS}

This work was supported by the Hixon Professorship at the California Institute of Technology, the Canadian Institute for Advanced Research, the Air Force Office of Scientific Research, and the Medical Research Council.

\section{REFERENCES}

Allman, J. 1977. Evolution of the visual system in the early primates. Prog. Psychobiol. Physiol. Psychol. 7: 1.

Ballard, D. 1986. Cortical connections and parallel processing: Structure and function. Behav. Brain Sci. 9:67.

Barlow, H. 1972. Single units and sensation: A neural doctrine for perception. Perception 1: 371 .

. 1979. The efficiency of detecting changes of density in random dot patterns. Vision Res. 18: 637

Bartlett, J. and R. Doty. 1974. Response of units in striate cortex of squirrel monkeys to visual and electrical stimuli. J. Neurophysiol. 37: 621.

Blasdel, G. and G. Salama. 1986. Voltage-sensitive dyes re veal a modular organization in monkey striate cortex. Nature 321: 579.

Burr, D. and J. Ross. 1979. How does binocular delay give information about depth. Vision Res. 19: 523.

Celio, M., L. Scharer, J. Morrison, A. Norman, and F. Bloom. 1986. Calbindin immunoreactivity alternates with cytochrome c-oxidase-rich zones in some layers of the primate visual cortex. Nature 323: 715 .

Condo, G., S. Florence, and V. Casagrande. 1987. Development of laminar and columnar patterns of cytochrome oxidase activity in galago visual cortex. Soc. Neurosci. Abstr. 13: 1025.

Derrington, A. and P. Lennie. 1984. Spatial and temporal contrast sensitivities of neurones in lateral geniculate nucleus of macaque. J. Physiol. 357: 219.

Horton, J. 1984. Cytochrome oxidase patches: A new cytoarchitectonic feature of monkey cortex. Philos. Trans. $R$. Soc. Land. B Biol. Sci. 304: 199

Horton, J. and D. Hubel. 1981. Regular patchy distribution of cytochrome oxidase staining in primate visual cortex of macaque monkey. Nature 292: 762

Jacobs, G. 1977. Visual capacities of the owl monkey (Aotus trivirgatus). 1. Spectral sensitivity and color vision. Vision Res. 17: 811 .

Jacobs, G. and J. Neitz. 1986. Spectral mechanisms and color vision in the tree shrew (Tupaia belangeri). Vision Res. 26: 291

Kayama, Y.. R. Riso, J. Bartlett, and R. Doty. 1979. Luxotonic responses of units in macaque striate cortex. $J$. Neurophysiol. 42; 1495.

Kuljis, R. and P. Rakic. 1990. Hypercolumns in primate visual cortex can develop in the absence of cues from photoreceptors. Proc. Natl. Acad. Sci. 87: 5303.

Livingstone, M. and D. Hubel. 1984. Anatomy and physiology of a color system in primate visual cortex. J. Neurosci. 4: 309 .

. 1987. Psychophysical evidence for separate channels for the perception of form, color, movement, and depth. $J$. Neurosci. 7: 3416

Maguire, W. and J. Baizer. 1982. Luminance coding of briefly presented stimuli in area 17 of the rhesus monkey. $J$. Neurophysiol. 47: 128.

Maler, L., S. Jande, and D. Lawson. 1984. Localization of vitamin $\mathrm{D}$-dependent calcium binding protein in the electrosensory and electromotor system of high frequency gymnotic fish. Brain Res. 301: 166

Marr, D. 1970. A theory for cerebral neocortex. Proc. R. Soc. Lond. B Biol. Sci. 176: 161. 
Martin, K. 1988. From enzymes to visual perception: A bridge too far? Trends Neurosci. 11: 380.

Martin, R. 1990. Primate origins and evolution. Chapman and Hall, London.

McGuinness, E., C. MacDonald, M. Sereno, and J. Allman. 1986. Primates without blobs: The distribution of cytochrome oxidase activity in striate cortex of Tarsius, Hapalemur and Cheirogaleus. Soc. Neurosci. Abstr. 12: 130 .

Needham, D. 1971. Machina carnis. Cambridge University Press, England.

Sclar, G.. P. Lennie, and D. DePriest. 1989. Contrast adaptation in striate cortex of macaque. Vision Res. 29: 747.

Silverman, M., D. Grosof, R. DeValois, and S. Elfar. 1989. Spatial-frequency organization in primate striate cortex. Proc. Natl. Acad. Sci. 86: 711.

Takahashi, T., C. Carr, N. Brecha, and M. Konishi. 1987. Calcium binding protein-like immunoreactivity labels the terminal field of nucleus laminaris of the barn owl. $J$. Neurosci. 7: 1843 .

Tootell, R., S. Hamilton, and M. Silverman. 1985. Topography of cytochrome oxidase activity in owl monkey cortex. J. Neurosci. 5: 2786.

Tootell, R., M. Silverman, S. Hamilton, R. DeValois, and E. Switkes. 1988a. Functional anatomy of macaque striate cortex. III. Color. J. Neurosci. 8: 1569.
Tootell, R., M. Silverman, S. Hamilton, E. Switkes, and R. DeValois. 1988b. Functional anatomy of macaque striate cortex. V. Spatial frequency. J. Neurosci. 8: 1610.

T'so, D. and C. Gilbert. 1988. The organization of chromatic and spatial interactions in primate striate cortex. $J$. Neurosci. 8: 1712.

Wikler, K. and P. Rakic. 1989. Immunocytochemical identification of cones in the retina of nocturnal and diurnal primates. Soc. Neurosci. Abstr. 15: 1206.

Wong-Riley, M. and E. Carroll. 1984. The effect of impulse blockage on cytochrome oxidase activity in the monkey visual system. Nature 222: 18 .

Wong-Riley. M. and T. Norton. 1988. Histochemical localization of cytochrome oxidase activity in the visual system of the tree shrew: Normal patterns and the effects of retinal impulse blockage. J. Comp. Neurol. 272: 562.

Wong-Riley, M., S. Tripathi, T. Trusk, and D. Hoppe. 1989. Effects of retinal impulse blockage on cytochrome oxidaserich zones in the macaque striate cortex. I. Quantitative electron-microscopic (EM) analysis of neurons. Vis. Neurosci. 2: 483.

Wright, P. 1989. The nocturnal primate niche in the new world. J. Hum. Evol. 18: 635 .

Zucker, S. and R. Hummel. 1986. Receptive fields and the representation of visual information. Human Neurobiol. 5: 121 . 